\title{
Cognitive reflection and the coronavirus conspiracy beliefs
}

\author{
Hashem Sadeghiyeh ${ }^{1, *}$, Iman Khanahmadi ${ }^{2}$, Parvaneh Farhadbeigi ${ }^{3}$, and Negar \\ Karimi $^{3}$ \\ ${ }^{1}$ Department of Psychology, University of Arizona, Tucson, Arizona, USA \\ ${ }^{2}$ Faculty of Law and Political Science, University of Tehran, Tehran, Iran \\ ${ }^{3}$ Cognitive Science Research Group, Academic Center for Education, Culture \\ and Research, Tehran, Iran \\ *Corresponding author: sadeghiyeh@arizona.edu
}

August 2, 2020

\begin{abstract}
The COVID-19 pandemic reminded us of how quickly conspiracy ideas can spread and how dire their consequences could be. One important question is what traits would predict susceptibility to conspiracy beliefs. Previous research pointed to one of those traits: reflective versus intuitive cognitive style. Here we examined how cognitive style correlates with founded and unfounded beliefs about the origin of COVID-19. A sample of 173 Iranians rated the likelihood of different beliefs about the origin of the new coronavirus and answered the original Cognitive Reflection Test (Frederick, 2005). In line with previous research, the reflective responses were negatively correlated with conspiratory beliefs and positively correlated with the founded statement (that the virus was spread from wild animals by chance). The reverse pattern was found for the intuitive responses. The results accrue more evidence in support of a relationship between reflective-analytic style of thinking and the tendency to reject conspiracy beliefs.
\end{abstract}

Keywords - cognitive reflection, intuitive, analytic style, conspiracy theory, misinformation, coronavirus, COVID-19, Iran

\section{Introduction}

Shortly after the outbreak of the new coronavirus (COVID-19), a variety of unfounded and conspiratory beliefs about the origin of the virus also spread across the globe. Although some conspiratory beliefs (e.g. moon landing conspiracy theories) may seem harmless, believing in others like the coronavirus conspiracy theories have significant and sometimes fatal consequences by making the believer less inclined to follow the recommended and mandated health policies by authorities (Pummerer, Lilleholt, Winter, \& Zettler, 2020; Erceg, Ružojčić, \& Galic, 2020; Freeman et al., 2020; Allington, Duffy, Wessely, Dhavan, \& Rubin, 2020). More generally, it has been shown that believing in conspiracy theories decreases social engagement (Butler, Koopman, \& Zimbardo, 1995), intentions to engage in politics (Jolley \& Douglas, 
2014), pro-environmental behaviors and care for the climate change (Uscinski \& Olivella, 2017; Jolley \& Douglas, 2014).

Conspiracy theories are ubiquitous and can be found in a variety of cultures (Sunstein \& Vermeule, 2009; Byford, 2011, Goertzel, 1994). In every culture, they are also pretty common in general population and may have enduring effects on crucial events (from the outbreak of an epidemic to moon landing and shooting Kennedy) or at least on our perception of those events (Dagnall, Drinkwater, Parker, Denovan, \& Parton, 2015; Swami, Chamorro-Premuzic, \& Furnham, 2010; Goertzel, 1994). After the assassination of John F. Kennedy by Lee Harvey Oswald, 80\% of Americans believed that Oswald didn't act lonely in shooting Kennedy (McCauley \& Jacques, 1979). In a poll by Stempel, Hargrove, and Stempel (2007), $36 \%$ of American respondents expressed at least some likelihood that US government assisted, or at least let 9/11 attacks happen. One out of three Americans believed that Barack Obama illegitimately became the US president (Uscinski \& Parent, 2014). The widespread acceptance or consideration of conspiracy theories show the persuasive and appealing nature of these ideas ((Dagnall et al., 2015; Byford, 2011).

McCauley and Jacques (1979) proposed that one of the reasons that conspiratory beliefs are popular is because they give us a sense of control and predictability. If disasters are due to chance, we don't have much control over them, but if they are the result of actions by some bad people, we may regain control by undermining them (Imhoff \& Bruder, 2014). If there are no definite answer to a crucial event or the official account seems not adequate, people tend to believe more in conspiracy theories (Drinkwater, Dagnall, \& Parker, 2012).

Some experimental evidence support the hypothesis that conspiratory beliefs may compensate for the lack of control. For example, Whitson and Galinsky (2008) reported that participants who didn't have control were more prone to perception of several illusions like seeing images in random noise, finding illusory patterns in stock market data, and perceiving conspiracies. In another experiment (Sullivan, Landau, \& Rothschild, 2010), participants who read statistics reporting deaths due to unpredictable causes like natural disasters and food poisoning (comparing to those who saw statistics on deaths due to predictable causes), strengthened their belief in the conspiratorial power of a political enemy. The authors argue that people exaggerate the influence of an enemy to compensate for their perceived reduction control over environment (Sullivan et al., 2010).

Many studies showed that those who endorse one conspiracy theory tend to endorse others (Goertzel, 1994; Drinkwater et al., 2012; Lewandowsky, Gignac, \& Oberauer, 2013), even contradictory ones (Wood, Douglas, \& Sutton, 2012). Dagnall et al. (2015) reported strong correlations between different measures of conspiracy beliefs. Also, conspiracy beliefs are strongly correlated with other forms of unfounded beliefs including paranormal, magical and superstitious ideas (Darwin, Neave, \& Holmes, 2011; Newheiser, Farias, \& Tausch, 2011, Lobato, Mendoza, Sims, \& Chin, 2014). These finding point to a possible general propensity to fall for conspiracies, a "coherent conspiratorial mindset" (Dagnall et al., 2015), or a "conspiracy mentality" (Moscovici, 1987).

If this is true, there should be some trends in personality traits that correlate with a conspiracy mentality. In fact, there are many studies that show those traits including low levels of interpersonal trust (Goertzel, 1994), high levels of openness to experience (Swami et al., 2010), low levels of agreeableness (Swami et al., 2011), feelings of powerlessness and low self-esteem (Abalakina-Paap, Stephan, Craig, \& Gregory, 1999), death-related anxiety (Newheiser et al., 2011), schizotypy, paranoia and delusional proneness (Dagnall et al., 2015; Darwin et al., 2011; Barron, Morgan, Towell, Altemeyer, \& Swami, 2014), and a Machiavellian approach to social interaction (Douglas \& Sutton, 2008).

Among all these traits, paranoia seems to has some basic features shared with conspiracy (Dagnall et al., 2015). Lobato et al. (2014) showed that beliefs in three categories of conspiracy, paranormal, and pseudo-scientific claims are correlated with each other. The basic features in conspiracy theories like suspicion and a fear of external agents, are also key features of paranoia (Holm, 2009). Abalakina-Paap et al. (1999) showed that beliefs in conspiracy theories are associated with feelings of being disadvantaged, powerlessness, alienation, and hostility. Paranoid beliefs, like conspiracy beliefs, are highly widespread (Pechey \& Halligan, 2011). There are some suggestions for the possible adaptive value of paranoid anxiety (Darwin et al., 2011). The features of paranoia (like a sense of vulnerability, reduced trust, 
and belief in others' harmful intent) could help us to detect social threats (Gilbert, Boxall, Cheung, \& Irons, 2005; Freeman et al., 2005). While many evidences point to a shared core between paranoia and conspiracy beliefs, there are some crucial differences (Dagnall et al., 2015; Byford, 2011). One important difference is the self-referenced nature of paranoia versus non-personal nature of conspiracy beliefs. A second difference is in their response to fear: paranoids withdraw and hide while conspiracists resist and fight (Dagnall et al., 2015).

Lewandowsky et al.(2013) reported that conspiracy beliefs were correlated with rejection of science. So it might be the case that endorsement of conspiracies is a result of deference to higher-order beliefs and failure to consider evidence thoroughly (Dagnall et al., 2015). This is in line with the idea that falling for conspiracy theories is a result of more intuitive and less reflective style of thinking. This relationship has been observed in other related traits; for example Irwin and Wilson (2013) found that both the "proneness to anomalous experiences" and "proneness to paranormal attributions" are positively correlated with the Intuitive-Experiential style of thinking but had no correlation with the Rational style. The intuitive versus rational style of thinking was measured by a self-report survey, "Rational-Experiential Inventory" (REI) (Pacini \& Epstein, 1999) which includes items like "I like to rely on my intuitive impressions" and "I enjoy solving problems that require hard thinking".

Maybe the most widespread used task to measure analytic cognitive style is Cognitive Reflection Test (CRT), originally described by Frederick (2005) as a 3-item numeric test. The questions are designed in a way to bring a fast (but wrong) response in mind. Consider the first question:

- A bat and a ball cost $\$ 1.10$ in total. The bat costs $\$ 1.00$ more than the ball. How much does the ball cost?

An immediate answer (10 cents) comes rapidly to mind that feels right and easy (System 1 in dualprocess theory (Kahneman, 2011). However by taking more time and reflecting on the question (System 2 of thinking), we may override the intuitive answer with the correct answer (5 cents). CRT is correlated with different decision-making parameters including temporal discounting, framing effect, and risk preferences (Frederick, 2005). CRT is also correlated with the self-report REI (Pearson's r=.2-.3) (Pennycook, Cheyne, Koehler, \& Fugelsang, 2016).

Besides decision-making, CRT has been shown to associate with heuristics-and-biases tasks (Toplak, West, \& Stanovich, 2011), religiosity (Shenhav, Rand, \& Greene, 2012, Gervais \& Norenzayan, 2012), paranormal beliefs (Pennycook, Cheyne, Seli, Koehler, \& Fugelsang, 2012), beliefs in fake news (Pennycook \& Rand, 2019), conservatism-liberalism (Deppe et al., 2015), and conspiracy beliefs (Ståhl \& van Prooijen. 2018; Swami, Voracek, Stieger, Tran, \& Furnham, 2014). Ståhl and van Prooijen (2018) reported a significant negative correlation between the 3-item CRT and 9-item specific conspiracy beliefs (including items like "The U.S.government had advance knowledge of the 9/11 attacks" and "The moon landing was a hoax") (van Prooijen, Douglas, \& De Inocencio, 2018), but not with a general 5-item conspiracy mentality scale (Bruder, Haffke, Neave, Nouripanah, \& Imhoff, 2013). Swami et al. (2014) experimentally elicited analytic thinking through a verbal fluency task and found a reduction in conspiracy beliefs.

The current study aims to test whether CRT scores can predict the degree of belief in conspiratory beliefs about the spread of COVID-19 in a sample of Iranians. Coronavirus conspiracies developed in a stressful and uncertain time that affected the lives of almost everybody; unlike many other conspiracy topics that have limited scope and audience, and may not apply to general population. A question to be answered here is that whether this factor affect the relationship between cognitive reflection and the susceptibility to conspiracy beliefs. Also, the majority of research on cognitive styles and their relationships with conspiracy beliefs and other traits, have been done in Western populations. In the current current study, we are going to see whether this relation also holds in a different Middle-Eastern culture. 


\section{Methods}

\section{Participants}

A total of 189 Iranians participated in our study. Sixteen participants were excluded from the final analysis due to incomplete data; given us a total of $\mathrm{N}=173$ participants (ages 18-87, mean $=34.4$, median $=$ 33; Females $=81$, Males $=92$ ). Figure 1 shows the distribution of four demographic variables (gender, age, education, marital status) in our final sample. Data was collected online through Qualtrics from March 4 to March 30, 2020. The period was when the outbreak of COVID-19 was growing very fast in Iran. Participants were recruited voluntarily through convenient sampling by sending invitations through email list-serves and social media (including linkedin, WhatsApp groups and Telegram channels). Survey was provided in both English and Persian languages. Out of the final 173 participants, 132 chose Persian and 41 chose English version. All participants gave informed consent and the study was approved by the ethics committee at the Shahid Beheshti University of Medical Sciences, Tehran.
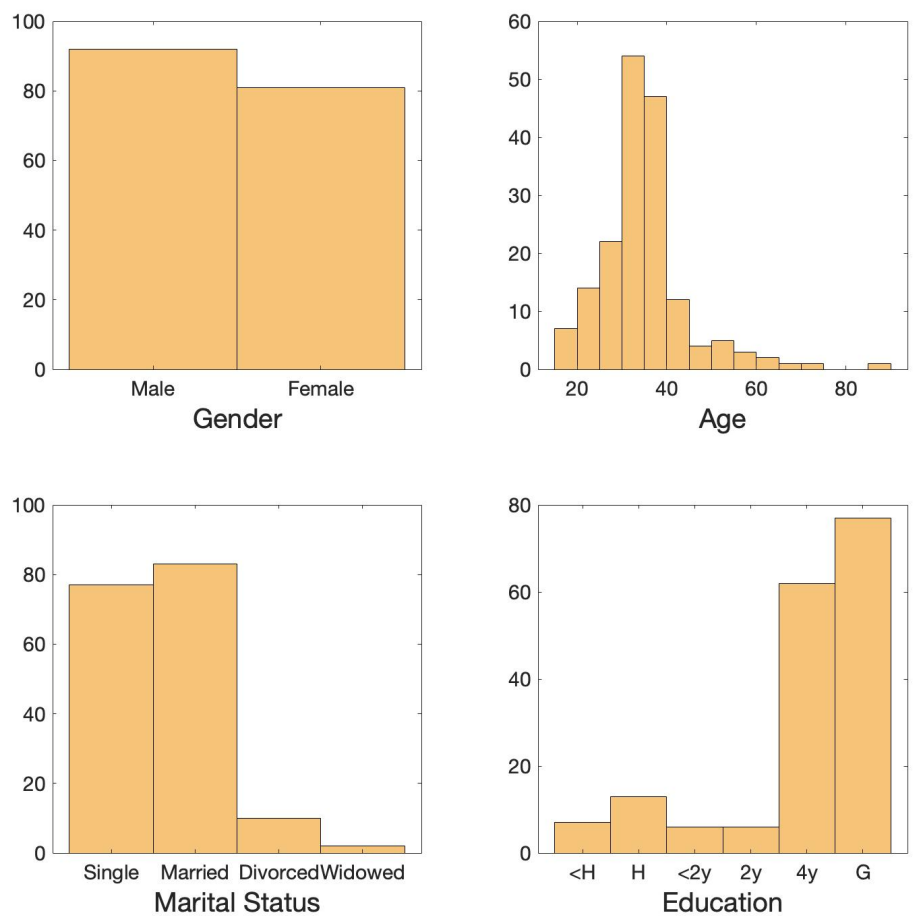

Figure 1: Histograms demonstrating the distribution of demographic parameters (gender, age, marital status, \& education) in our participants. The y-axis shows the frequency or the number of occurrences per each value on the $\mathrm{x}$-axis.

$<\mathrm{H}$ : Some high school or less

H: High school diploma

$<2 \mathrm{y}$ : Some college (1 yr. to less than 2 yrs.)

2y: Two-year college degree (A.A.)

4y: Four-year college degree (B.A. or B.S.)

G: MA/PhD, MD, MBA, Law Degree

\section{Materials}

After giving their consent (Page 1), participants rated their beliefs on COVID-19 outbreak (Page 2). Then they were given the original Cognitive Reflection Test (Frederick, 2005) on page 3 and lastly they answered demographic questions on page 4 . The whole questionnaire was provided 
in both English and Persian (Farsi) and participants were free to choose which language they wanted to answer the survey (132 chose Farsi, 41 chose English).

\section{Beliefs on COVID-19 outbreak}

Participants rated their beliefs in the following ten statements on a scale of 0 (extremely unlikely) to 100 (extremely likely):

- It was built by China to undermine USA market.

- It was built by USA to undermine China market.

- It was built by USA to destabilize Iran.

- It was built by Russia to interfere with international trades.

- It accidentally spread out of a secret Chinese laboratory, no one wanted to spread it intentionally.

- It spread to humans from wild animals by pure chance.

- There is no coronavirus threat. It's all fake news to terrify people.

- It is a divine punishment due to the sins of humanity.

- Nobody has a clue how it spread.

- We don't know who made it, but it is man-made for sure.

\section{Cognitive Reflection Test}

We used the original 3-item Cognitive Reflection Test (Frederick, 2005):

"Below are three items that vary in difficulty. Answer as many as you can.

1. A bat and a ball cost $\$ 1.10$ in total. The bat costs $\$ 1.00$ more than the ball. How much does the ball cost? - cents

2. If it takes 5 machines 5 minutes to make 5 widgets, how long would it take 100 machines to make 100 widgets? - minutes

3. In a lake, there is a patch of lily pads. Every day, the patch doubles in size. If it takes 48 days for the patch to cover the entire lake, how long would it take for the patch to cover half of the lake? _ days."

\section{Demographic Questions}

In the last page participants declared their age, gender, marital status, education level and the city in which they answered the survey. 


\section{Results}

\section{Descriptive Statistics}

\section{Beliefs}

Figure 1 shows the distributions of likelihoods assigned to each of the 10 statements. As we can see, on each statement, the majority respondents assigned a very low or zero probability. But there are significant differences in the shape of distribution between different beliefs. Table 1 shows the mean and standard deviation (SD) for the likelihoods assigned to each statement. The founded belief (statement 6) has the highest mean $=45$ (on a 0-100 scale). The next highest was the belief that the virus was "man-made" (statement 10) with a mean of 42.6. The lowest likelihood assigned $(=8)$ was for the "fake news" and "divine punishment" beliefs.
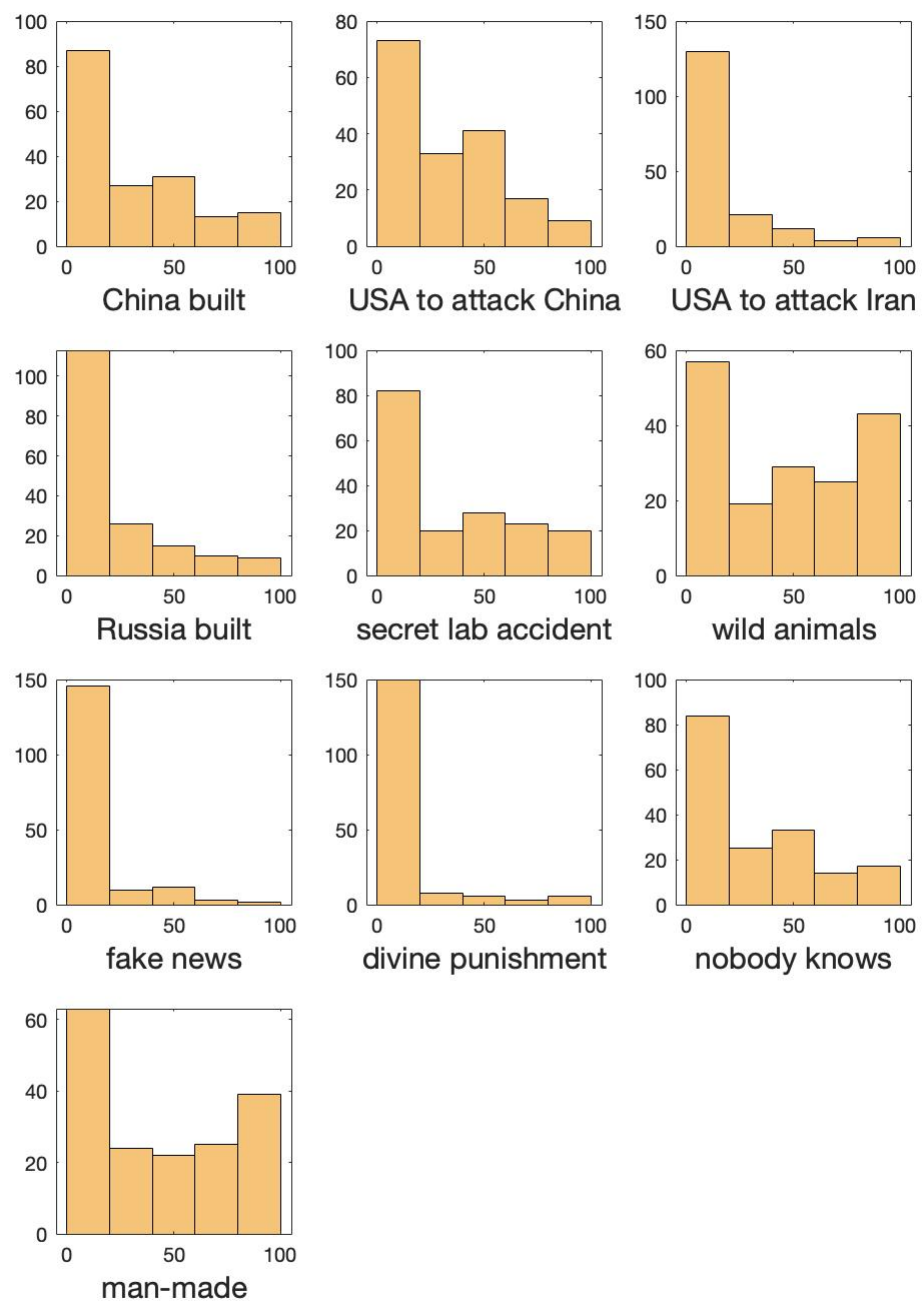

Figure 2: Histograms demonstrating the distribution of the likelihoods assigned to each of the 10 statements. The $\mathrm{y}$-axis shows the number of participants per each value on the $\mathrm{x}$-axis (likelihoods 0-100). 
Table 1: Mean and Standard deviation of likelihoods (0-100) assigned to each statement

\begin{tabular}{clcccc}
\hline$\#$ & Statement & Min & Max & Mean & SD \\
\hline \hline 6 & It spread to humans from wild animals by pure chance. & 0 & 100 & 45.02 & 35.85 \\
10 & We dont know who made it, but it is man-made for sure. & 0 & 100 & 42.64 & 36.79 \\
5 & It accidentally spread out of a secret Chinese laboratory, & 0 & 100 & 32.42 & 32.12 \\
& no one wanted to spread it intentionally. & & & & \\
9 & Nobody has a clue how it spread. & 0 & 100 & 29.92 & 31.20 \\
2 & It was built by USA to undermine China market. & 0 & 100 & 29.61 & 28.04 \\
1 & It was built by China to undermine USA market. & 0 & 100 & 27.88 & 30.29 \\
4 & It was built by Russia to interfere with international trades. & 0 & 100 & 18.83 & 26.24 \\
3 & It was built by USA to destabilize Iran. & 0 & 100 & 13.02 & 23.25 \\
8 & It is a divine punishment due to the sins of humanity. & 0 & 100 & 8.25 & 21.79 \\
7 & There is no coronavirus threat. Its all fake news to terrify people. & 0 & 100 & 8.15 & 18.58 \\
\hline \hline
\end{tabular}

\section{CRT scores}

Figure 3 shows the distributions of the total reflective $\&$ intuitive responses in CRT. Table 2 shows the mean and standard deviation for intuitive and reflective responses to each 3 items in CRT and the total reflection and intuition scores. The average of reflective responses in our sample is 1.27 which is comparable to other web-based studies (Frederick, 2005).
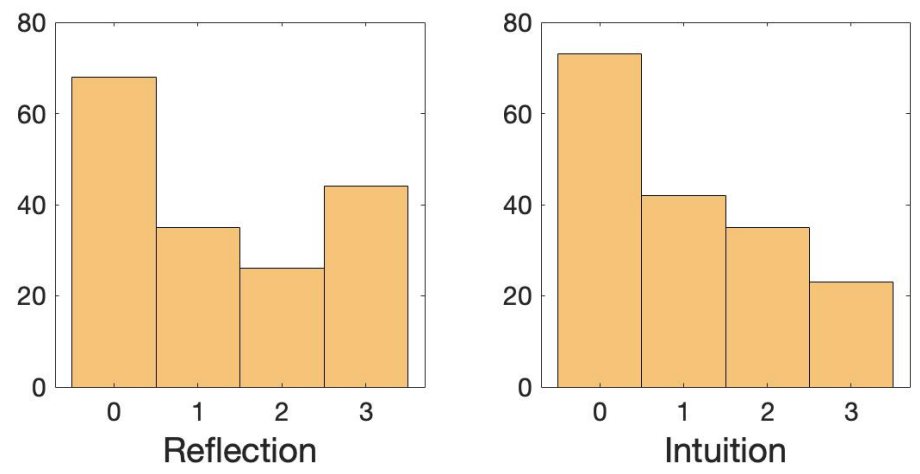

Figure 3: Histograms demonstrating the distributions of the total score of reflective (correct) and intuitive responses to the Cognitive Reflection Test in our sample of 173 participants. The $\mathrm{y}$-axis shows the frequency or the number of occurrences per each value on the $\mathrm{x}$-axis.

We may expect to see a perfect negative correlation between Intuition and Refection scores, however this correlation is $\mathrm{r}(171)=-0.68 ; \mathrm{p}<0.001$ since there are other options in responding to CRT. Overall, there are 4 possibilities:

1. The correct (= reflective) responses which are 5, 5, 47 to items 1-3 respectively.

2. The wrong-intuitive responses which are 10, 100, 24 to items 1-3 respectively.

3. The wrong-other responses which are any other responses than the reflective and the intuitive ones.

4. The not-answered or left-blank responses. 
Table 2: Mean and Standard Deviation for intuitive and reflective responses to each CRT's items and the total reflection and intuition scores

\begin{tabular}{lcccc}
\hline CRT Scores & Min & Max & Mean & SD \\
\hline \hline Intuition & 0 & 3 & $\mathbf{1 . 0 5}$ & $\mathbf{1 . 0 8}$ \\
Intuition-1 & 0 & 1 & 0.44 & 0.50 \\
Intuition-2 & 0 & 1 & 0.33 & 0.47 \\
Intuition-3 & 0 & 1 & 0.28 & 0.45 \\
Reflection & 0 & 3 & $\mathbf{1 . 2 7}$ & $\mathbf{1 . 2 2}$ \\
Reflection-1 & 0 & 1 & 0.40 & 0.49 \\
Reflection-2 & 0 & 1 & 0.43 & 0.50 \\
Reflection-3 & 0 & 1 & 0.43 & 0.50 \\
\hline \hline
\end{tabular}

Figure 4 shows the percentage of these four kinds of responses to each item in CRT. As we can see, the correct response rate is almost the same (around 40-43\%) for each item. However, the intuitive response rate is $44 \%$ for item 1 (the classic bat question) and it drops to $33 \%$ and $28 \%$ for items 2 and 3 respectively.

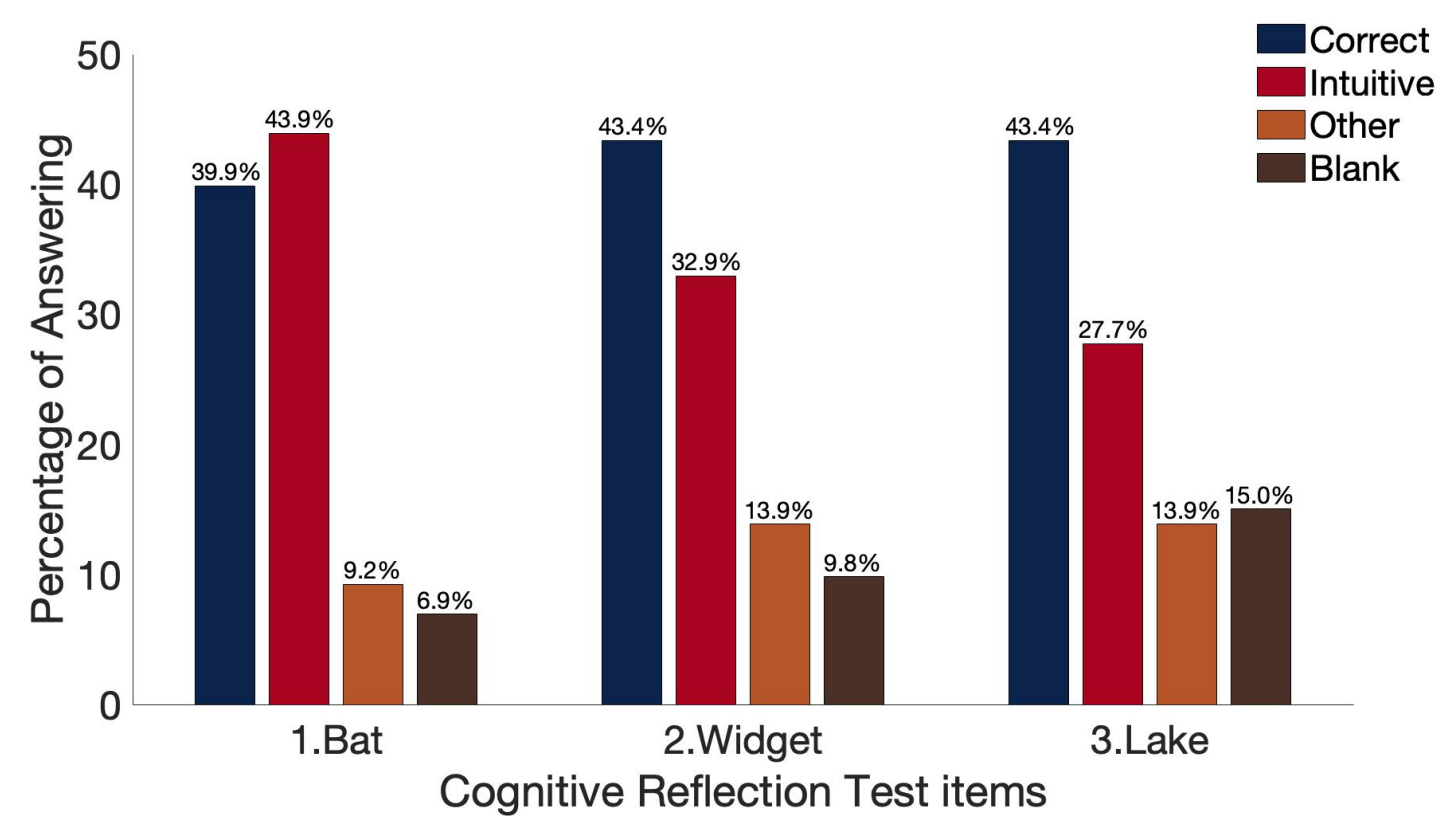

Figure 4: Percentage of correct (reflective), wrong-intuitive, wrong-other \& left-blank responses to each of the three CRT's items.

\section{Correlations between Beliefs}

Table 3 shows the correlations between the 10 statements with each other. As expected, there is a negative correlation between the founded belief (statement 6) and most of the conspiratory beliefs. Conspiratory beliefs are those unfounded beliefs that imply an "intential" action by some individuals in either making the virus (statements 1-4 and 10) or spreading false information about it (statement 7). Also in line with previous studies, the conspiratory beliefs are 
mostly correlated with each other including the contradictory ones (e.g. "It was built by Russia" is positively correlated with "It was built by USA", $\mathrm{r}(171)=0.26 ; \mathrm{p}<0.001$ and also with "It was built by China", $\mathrm{r}(171)=0.15 ; \mathrm{p}<0.05)$.

Table 3: Pearson correlation coefficients table for the 10 statements

\begin{tabular}{|c|c|c|c|c|c|c|c|c|c|c|}
\hline Statement & 1 & 2 & 3 & 4 & 5 & 6 & 7 & 8 & 9 & 10 \\
\hline$\overline{11}$ & - & & & & & & & & & \\
\hline 2 & $0.12^{\dagger}$ & - & & & & & & & & \\
\hline 3 & $-0.13^{\dagger}$ & $0.36^{* * *}$ & - & & & & & & & \\
\hline 4 & $0.15^{*}$ & $0.26^{* * *}$ & $0.21^{* *}$ & - & & & & & & \\
\hline 5 & $0.12^{\dagger}$ & $0.22^{* *}$ & $0.15^{*}$ & $0.16^{*}$ & - & & & & & \\
\hline 6 & $-0.42^{* * *}$ & $-0.20^{* *}$ & $-0.13^{\dagger}$ & -0.10 & 0.08 & - & & & & \\
\hline 7 & $0.17^{*}$ & 0.06 & $0.14^{\dagger}$ & 0.09 & 0.07 & -0.04 & - & & & \\
\hline 8 & 0.00 & 0.04 & 0.05 & -0.05 & 0.09 & -0.01 & $0.23^{* *}$ & - & & \\
\hline 9 & -0.02 & -0.07 & -0.01 & 0.10 & 0.11 & $0.18^{*}$ & $0.16^{*}$ & 0.02 & - & \\
\hline 10 & $0.30^{* * *}$ & $0.33^{* * *}$ & $0.22^{* *}$ & 0.11 & 0.12 & $-0.40^{* * *}$ & 0.04 & 0.01 & 0.05 & - \\
\hline \multicolumn{11}{|l|}{${ }^{\dagger} \mathrm{p}<0.10$} \\
\hline \multicolumn{11}{|l|}{${ }^{*} \mathrm{p}<0.05$} \\
\hline \multicolumn{11}{|l|}{${ }^{* *} \mathrm{p}<0.01$} \\
\hline${ }^{* * *} \mathrm{p}<0.001$ & & & & & & & & & & \\
\hline
\end{tabular}

\section{Correlations between CRT and Conspiratory Beliefs}

Table 4 demonstrates the Spearman's Rank correlation coefficients between different beliefs and both Reflection and Intuition scores. While all the conspiratory beliefs have negative correlations with cognitive reflection and positive correlation with intuition, two of them stand out as significant in correlation with both reflection and intuition scores: the general belief that the virus was man-made and the belief that it was manufactured by China.

To find a single measure for conspiratory beliefs, we can either average over the 6 conspiratory statements $(1-4,7, \& 10)$ or take the maximum out of them. Both methods yielded similar results in the current study. We stick to the maximum measure since it makes more sense conceptually. As it can be seen in Figure 5 as well, the Spearman's rank correlation coefficient between Cognitive Reflection and the maximum of conspiracy beliefs (controlling for gender, age, education, marital status and the chosen language) is $\rho(171)=-0.32 ; p<0.001$ and between Cognitive Reflection and the founded belief (statement 6) is $\rho(171)=0.34 ; p<0.001$. For the intuitive responses, the correlation with conspiracy beliefs is $\rho=0.29 ; p<0.001$ and with the founded belief is $\rho=-0.27 ; p<0.001$. These results are in line with previous research showing a negative correlation between analytic cognitive style and unfounded beliefs. 

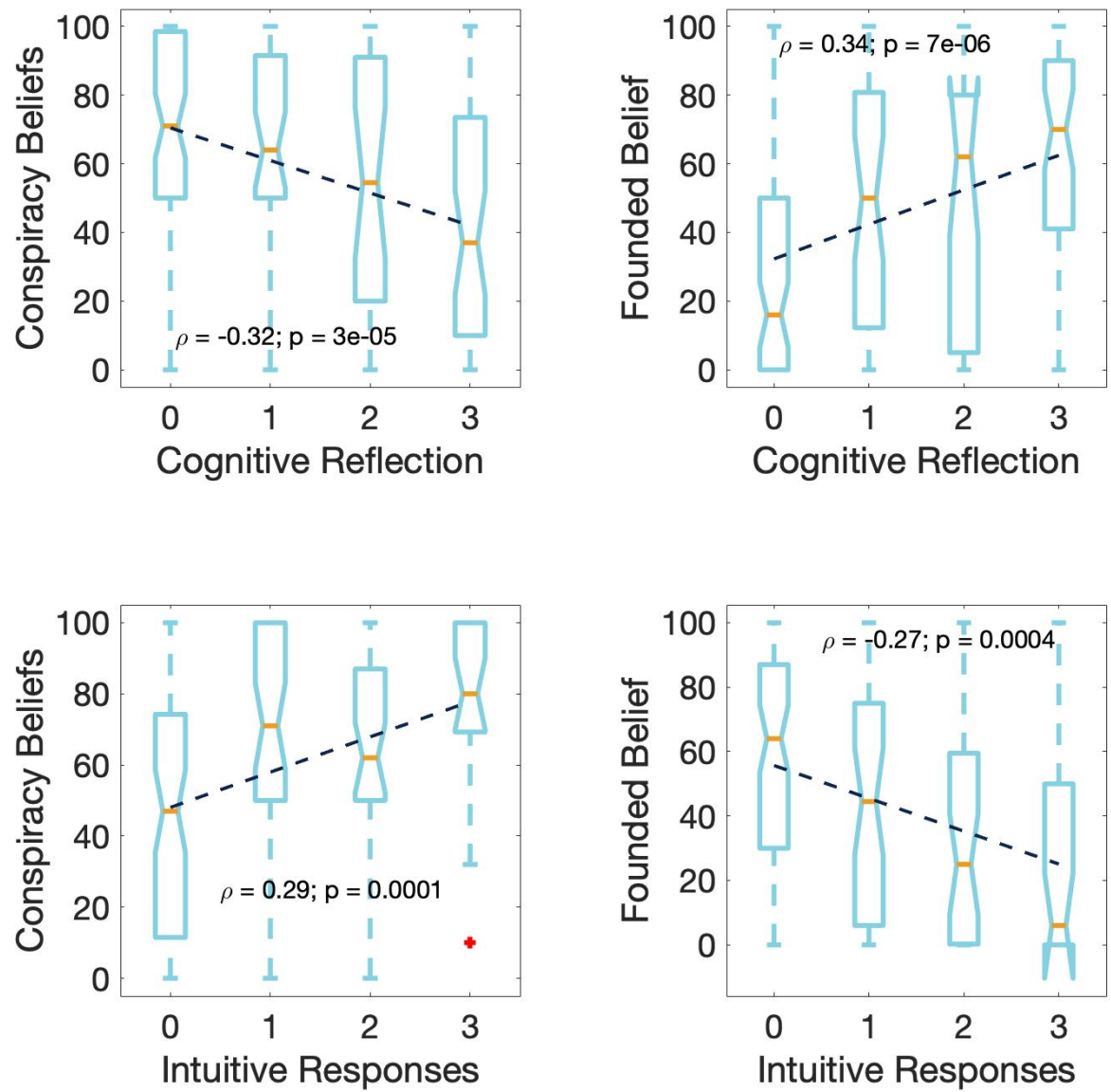

Figure 5: Spearman's Rank correlations between cognitive reflection (top) and intuition scores (bottom) with the degree of conspiracy beliefs (left) and the founded explanation (right)

Table 4: Spearman correlations between each statement and reflective/intuitive responses to CRT

\begin{tabular}{llcccc}
\hline & & \multicolumn{2}{c}{ Reflection } & \multicolumn{2}{c}{ Intuition } \\
$\#$ & statement & $\mathrm{r}$ & $\mathrm{p}$ & $\mathrm{r}$ & $\mathrm{p}$ \\
\hline \hline 1 & China built & $\mathbf{- 0 . 2 2}$ & 0.005 & $\mathbf{0 . 2 5}$ & 0.001 \\
2 & USA to attack China & -0.04 & 0.579 & 0.06 & 0.434 \\
3 & USA to attack Iran & -0.10 & 0.198 & 0.05 & 0.523 \\
4 & Russia built & -0.09 & 0.243 & $\mathbf{0 . 1 8}$ & 0.018 \\
5 & secret lab accident & -0.01 & 0.874 & 0.00 & 0.979 \\
6 & wild animals & $\mathbf{0 . 3 4}$ & $<.001$ & $\mathbf{- 0 . 2 7}$ & $<.001$ \\
7 & fake news & -0.10 & 0.207 & 0.05 & 0.501 \\
8 & divine punishment & 0.01 & 0.917 & -0.06 & 0.466 \\
9 & nobody knows & -0.01 & 0.922 & 0.06 & 0.433 \\
10 & man-made & $\mathbf{- 0 . 2 3}$ & 0.002 & $\mathbf{0 . 2 0}$ & 0.008 \\
\hline \hline
\end{tabular}




\section{Conclusion}

In the current study, we investigated the relations between reflective versus intuitive cognitive styles and the degree of believe in conspiratory ideas about the origin of COVID-19 in a sample of Iranians. In line with previous research on other kinds of conspiracy theories and in different populations, we have found a significant positive correlation between cognitive reflection scores and the degree to endorse the founded belief ("spread from wild animals by chance"), and a negative correlation between cognitive reflection scores and the conspiracy beliefs (the maximum likelihood assigned to statements 1-4, 7, and 10).

Ståhl and van Prooijen (2018) suggest two reasons that why impoverished analytic skills may lead to unfounded beliefs. Maybe the most salient reason is that some unfounded beliefs, including many conspiratory beleifs, have strong intuitive appeal (Norenzayan \& Gervais, 2013, Barrett, 2000). So if a person rely more on intuitive thinking than the analytic thinking, he or she should be more susceptible to the unfounded beliefs. Another reason might be that people with less analytic skills are less able to distinguish strong from weak evidences, and this may lead to the acceptance of unfunded beliefs which are mainly based on anecdotes and innuendo (Ståhl \& van Prooijen, 2018).

One limitation of our study is that although we measured participants' level of education, we didn't include a measure of general cognitive ability. While many studies showed that the effect of analytic thinking is beyond the general cognitive ability in explaining many phenomena including some decision-making parameters, heuristics-biases, religiosity and paranormal beliefs (Frederick, 2005; Toplak et al., 2011; Pennycook et al., 2012), Ståhl and van Prooijen (2018) suggest that general cognitive ability rather than reflective style of thinking per se, was responsible for the observed relationship in their study between CRT and paranormal and conspiratory beliefs. Also Sinayev and Peters (2015) demonstrated that in their study, correlations between decision performance and scores on the CRT were not sufficient to implicate the overriding of intuitions in the decision-making biases, and it was "numeric ability" that seemed to be the key mechanism instead. However, others showed that CRT is not just a numeracy test and indeed measures cognitive reflection. (Campitelli \& Gerrans, 2014).

\section{Conflicts of Interest}

The authors declare that they have no conflict of interest.

\section{Funding}

The authors have no funding to disclose.

\section{Compliance with Ethical Standards}

All procedures performed in experiments were in accordance with the ethical standards of the institutional research committee and with the 1964 Helsinki Declaration and its later amendments or comparable ethical standards.

\section{Informed Consent}

Informed consent was obtained from all individual adult participants included in the study. 


\section{Data Availability Statement}

The data and Matlab codes are available at https://github.com/hashem20/conspiracy-CRT

\section{References}

Abalakina-Paap, M., Stephan, W. G., Craig, T., \& Gregory, W. L. (1999). Beliefs in conspiracies. Political Psychology, 20(3), 637-647.

Allington, D., Duffy, B., Wessely, S., Dhavan, N., \& Rubin, J. (2020). Health-protective behaviour, social media usage, and conspiracy belief during the COVID-19 public health emergency. Psychological Medicine.

Barrett, J. L. (2000). Exploring the natural foundations of religion. Trends in Cognitive Sciences, 4(1), 29-34.

Barron, D., Morgan, K., Towell, T., Altemeyer, B., \& Swami, V. (2014, 11). Associations between schizotypy and belief in conspiracist ideation. Personality and Individual Differences, 70, 156-159.

Bruder, M., Haffke, P., Neave, N., Nouripanah, N., \& Imhoff, R. (2013, 4). Measuring Individual Differences in Generic Beliefs in Conspiracy Theories Across Cultures: Conspiracy Mentality Questionnaire. Frontiers in Psychology, 4, 225.

Butler, L. D., Koopman, C., \& Zimbardo, P. G. (1995). The Psychological Impact of Viewing the Film "JFK": Emotions, Beliefs, and Political Behavioral Intentions. Political Psychology, 16(2), 237.

Byford, J. (2011). Conspiracy theories: A critical introduction. Springer.

Campitelli, G., \& Gerrans, P. (2014). Does the cognitive reflection test measure cognitive reflection? A mathematical modeling approach. Memory and Cognition, 42(3), 434447.

Dagnall, N., Drinkwater, K., Parker, A., Denovan, A., \& Parton, M. (2015, 2). Conspiracy theory and cognitive style: A worldview. Frontiers in Psychology, 6(2), 206.

Darwin, H., Neave, N., \& Holmes, J. $(2011,6)$. Belief in conspiracy theories. The role of paranormal belief, paranoid ideation and schizotypy. Personality and Individual Differences, 50(8), 1289-1293.

Deppe, K. D., Gonzalez, F. J., Neiman, J. L., Jacobs, C., Pahlke, J., Smith, K. B., \& Hibbing, J. R. (2015). Reflective liberals and intuitive conservatives: A look at the cognitive reflection test and ideology. Judgment and Decision Making, 10(4), 314-331.

Douglas, K. M., \& Sutton, R. M. (2008). The hidden impact of conspiracy theories: Perceived and actual influence of theories surrounding the death of Princess Diana. Journal of Social Psychology, 148(2), 210-222.

Drinkwater, K., Dagnall, N., \& Parker, A. (2012). Reality testing, Conspiracy theories, and Paranormal beliefs. The Journal of Parapsycholog, 76(1), 57-77.

Erceg, N., Ružojčić, M., \& Galic, Z. (2020). Misbehaving in the Corona Crisis: The Role of Anxiety and Unfounded Beliefs. PsyArXiv [Working Paper].

Frederick, S. (2005). Cognitive reflection and decision making. Journal of Economic Perspectives, 19(4), 25-42.

Freeman, D., Garety, P. A., Bebbington, P. E., Smith, B., Rollinson, R., Fowler, D., ... Dunn, G. $(2005,5)$. Psychological investigation of the structure of paranoia in a non-clinical population. British Journal of Psychiatry, 186(5), 427-435. 
Freeman, D., Waite, F., Rosebrock, L., Petit, A., Causier, C., East, A., ... Lambe, S. (2020). Coronavirus Conspiracy Beliefs, Mistrust, and Compliance with Government Guidelines in England. Psychological Medicine, 1-13.

Gervais, W. M., \& Norenzayan, A. (2012). Analytic thinking promotes religious disbelief. Science, 336(6080), 493-496.

Gilbert, P., Boxall, M., Cheung, M., \& Irons, C. (2005). The relation of paranoid ideation and social anxiety in a mixed clinical population. Clinical Psychology and Psychotherapy, 12(2), 124-133.

Goertzel, T. (1994). Belief in Conspiracy Theories. Political Psychology, 15(4), 731-742.

Holm, N. (2009, 10). Conspiracy theorizing surveillance: Considering modalities of paranoia and conspiracy in surveillance studies. Surveillance and Society, 7(1), 36-48.

Imhoff, R., \& Bruder, M. (2014). Speaking (Un-)truth to power: Conspiracy mentality as a generalised political attitude. European Journal of Personality, 28(1), 25-43.

Irwin, H., \& Wilson, K. (2013). Anomalous Experiences and the Intuitive -Experiential Style of Thinking. Journal of the Society for Psychical research, 77.2(911), 65-71.

Jolley, D., \& Douglas, K. M. (2014). The social consequences of conspiracism: Exposure to conspiracy theories decreases intentions to engage in politics and to reduce one's carbon footprint. British Journal of Psychology, 105(1), 35-56.

Kahneman, D. (2011). Thinking, Fast and Slow. Macmillan.

Lewandowsky, S., Gignac, G. E., \& Oberauer, K. (2013). The Role of Conspiracist Ideation and Worldviews in Predicting Rejection of Science. PLoS ONE, 8(10).

Lobato, E., Mendoza, J., Sims, V., \& Chin, M. (2014). Examining the relationship between conspiracy theories, paranormal beliefs, and pseudoscience acceptance among a university population. Applied Cognitive Psychology, 28(5), 617-625.

McCauley, C., \& Jacques, S. (1979). The popularity of conspiracy theories of presidential assassination: A Bayesian analysis. Journal of Personality and Social Psychology, 37(5), 637-644.

Moscovici, S. (1987). The Conspiracy Mentality. In Changing conceptions of conspiracy (pp. 151-169). Springer New York.

Newheiser, A. K., Farias, M., \& Tausch, N. (2011). The functional nature of conspiracy beliefs: Examining the underpinnings of belief in the Da Vinci Code conspiracy. Personality and Individual Differences, 51(8), 1007-1011.

Norenzayan, A., \& Gervais, W. M. (2013). The origins of religious disbelief. Trends in Cognitive Sciences, 17(1), 20-25.

Pacini, R., \& Epstein, S. (1999). The relation of rational and experiential information processing styles to personality, basic beliefs, and the ratio-bias phenomenon. Journal of Personality and Social Psychology, 76(6), 972-987.

Pechey, R., \& Halligan, P. (2011). The prevalence of delusion-like beliefs relative to sociocultural beliefs in the general population. Psychopathology, 44(2), 106-115.

Pennycook, G., Cheyne, J. A., Koehler, D. J., \& Fugelsang, J. A. (2016). Is the cognitive reflection test a measure of both reflection and intuition? Behavior Research Methods, 48(1), 341-348.

Pennycook, G., Cheyne, J. A., Seli, P., Koehler, D. J., \& Fugelsang, J. A. (2012). Analytic cognitive style predicts religious and paranormal belief. Cognition, 123(3), 335-346.

Pennycook, G., \& Rand, D. G. (2019, 7). Lazy, not biased: Susceptibility to partisan fake news is better explained by lack of reasoning than by motivated reasoning. Cognition, 188, $39-50$. 
Pummerer, L., Lilleholt, L., Winter, K., \& Zettler, I. (2020). Societal effects of corona conspiracy theories. PsyArXiv.

Shenhav, A., Rand, D. G., \& Greene, J. D. (2012). Divine intuition: Cognitive style influences belief in God. Journal of Experimental Psychology: General, 141(3), 423-428.

Sinayev, A., \& Peters, E. (2015, 5). Cognitive reflection vs. calculation in decision making. Frontiers in Psychology, 6(5), 532.

Ståhl, T., \& van Prooijen, J. W. (2018). Epistemic rationality: Skepticism toward unfounded beliefs requires sufficient cognitive ability and motivation to be rational. Personality and Individual Differences, 122, 155-163.

Stempel, C., Hargrove, T., \& Stempel, G. H. (2007, 6). Media use, social structure, and belief in 9/11 conspiracy theories. Journalism and Mass Communication Quarterly, 84(2), 353372.

Sullivan, D., Landau, M. J., \& Rothschild, Z. K. (2010). An Existential Function of Enemyship: Evidence That People Attribute Influence to Personal and Political Enemies to Compensate for Threats to Control. Journal of Personality and Social Psychology, 98(3), 434-449.

Sunstein, C. R., \& Vermeule, A. (2009). Conspiracy theories: Causes and cures. Journal of Political Philosophy, 17(2), 202-227.

Swami, V., Chamorro-Premuzic, T., \& Furnham, A. (2010). Unanswered Questions: A Preliminary Investigation of Personality and Individual Difference Predictors of 9/11 Conspiracist Beliefs. Applied Cognitive Psychology, 24, 749-761.

Swami, V., Coles, R., Stieger, S., Pietschnig, J., Furnham, A., Rehim, S., \& Voracek, M. (2011). Conspiracist ideation in Britain and Austria: Evidence of a monological belief system and associations between individual psychological differences and real-world and fictitious conspiracy theories. British Journal of Psychology, 102(3), 443-463.

Swami, V., Voracek, M., Stieger, S., Tran, U. S., \& Furnham, A. (2014). Analytic thinking reduces belief in conspiracy theories. Cognition, 133(3), 572-585.

Toplak, M. E., West, R. F., \& Stanovich, K. E. (2011, 5). The Cognitive Reflection Test as a predictor of performance on heuristics-and-biases tasks. Memory and Cognition, 39(7), 1275-1289.

Uscinski, J. E., \& Olivella, S. (2017). The conditional effect of conspiracy thinking on attitudes toward climate change. Research and Politics, 4(4).

Uscinski, J. E., \& Parent, J. M. (2014). American Conspiracy Theories. Springer.

van Prooijen, J. W., Douglas, K. M., \& De Inocencio, C. (2018). Connecting the dots: Illusory pattern perception predicts belief in conspiracies and the supernatural. European Journal of Social Psychology, 48(3), 320-335.

Whitson, J. A., \& Galinsky, A. D. (2008). Lacking control increases illusory pattern perception. Science, 322(5898), 115-117.

Wood, M. J., Douglas, K. M., \& Sutton, R. M. (2012). Dead and alive: Beliefs in contradictory conspiracy theories. Social Psychological and Personality Science, 3(6), 767-773. 